\title{
Kontroversi peran studi elektrofisiologi pada sindrom brugada
}

\author{
Yoga Yuniadi
}

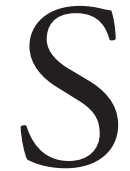
indrom Brugada adalah suatu abnormalitas sistem listrik jantung yang merupakan predisposisi terjadinya takikardia ventrikel dan hilang kesadaran. Takikardia ventrikel dapat berhenti spontan dan pasien pulih dari sinkop lalu berobat dengan keluhan sinkop, atau takikardia berdegenerasi menjadi fibrilasi ventrikel (FV)dan menyebabkan kematian jantung mendadak. Oleh karena itu sangat penting mengenal gambaran EKG sindrom Brugada lalu melakukan stratifikasi risiko yang cermat.

Salah satu yang menjadi perdebatan hangat adalah stratifikasi risiko sindrom Brugada melalui tindakan studi elektrofisiologi (SEF). Nilai prediktif induksi aritmia ventrikel saat SEF masih kontroversial. Studi yang melibatkan 408 pasien sindrom Brugada tanpa riwayat henti jantung menunjukkan bahwa pasien dengan indusibilitas FV memiliki risiko kematian jantung mendadak karena FV enam kali lipat dalam pengamatan 2 tahun. ${ }^{1}$ Akan tetapi studi multisenter dari Eropa, ${ }^{2,3}$ Jepang $^{4,5}$ dan beberapa metaanalisis, ${ }^{6,7}$ tidak menunjukkan hasil yang positif sehingga indikasi SEF untuk stratifikasi risiko sindrom Brugada hanya IIb pada tahun 2013 (Gambar 1). Metaanalisis ${ }^{8}$ yang lain memperlihatkan hasil yang positif yaitu ketika presentasi klinis pasien sindrome Brugada dipisahkan

\section{Alamat Korespondensi}

Dr. dr. Yoga Yuniadi, SpJP. Divisi Aritmia, Departemen Kardiologi dan Kedokteran Vaskular, FKUI dan Pusat Jantung Nasional Harapan Kita, Jakarta. E-mail: yogay136@gmail.com antara sinkop dan asimtomatik dalam analisanya. Analisa dengan pemisahan presentasi klinis ini tidak dilakukan pada metaanalisis sebelumnya. Sayang sekali metaanalisis ini tidak mengikutsertakan registri PRELUDE $^{2}$ karena tidak ada data presentasi klinis yang diinginkan. Selain tentang presentasi klinis, kelemahan studi prospektif pada sindrom Brugada yang ada hanya memiliki masa pengamatan sekitar 40 bulan yang cukup sebetulnya tidak cukup panjang karena pasien sindrom Brugada tetap memiliki risiko kematian jantung mendadak sepanjang hidupnya. Tampaknya dibutuhkan suatu studi prospektif jangka panjang yang lebih besar dengan identifikasi presentasi klinis yang jelas untuk dapat memutuskan kegunaan SEF untuk stratifikasi risiko kematian jantung mendadak pada sindrom Brugada.

Baru-baru ini sebuah studi kohort retrospektif yang dipublikasi dalam majalah Circulation Arrhythmias and Electrophysiology menjadi jawaban penting kontroversi di atas. Sieira $\mathrm{dkk}^{9}$ melakukan analisis data sindrom Brugada selama 20 tahun. Peneliti menganalisa 404 pasien sindrom Brugada type 1 dari data laboratorium Dr. Pedro Brugada. Sebanyak 404 pasien konsekutif menjadi subyek penelitian ini, 18.1\% di anataranya berhasil diinduksi aritmia ventrikel saat SEF. Dalam observasi selama $74.3 \pm 57.3$ bulan (median 57.3 bulan) terdapat 25 kejadian aritmik yang terdiri dari $16(21.9 \%)$ subyek pada kelompok yang berhasil diinduksi aritmia ventrikel saat SEF dan 9 (2.7\%) subyek pada kelompok yang tidak dapat diinduksi. Kejadian aritmia yang dimaksud di atas terdiri dari 24 appropriate ICD (implantable cardioverter defibrillator) 
shocks dan 1 resusitasi karena henti jantung pada pasien tanpa ICD. Dengan demikian rasio hazard aritmia ventrikel terinduksi saat SEF adalah 8.1 untuk kejadian aritmik di kemudian hari $(\mathrm{p}<0.01)$. Kurva kesintasan Kaplan Meier menunjukkan event free survival sebesar $96.8 \%$ hingga 99\% dalam 1, 5, 10 dan 15 tahun pada kelompok yang tidak terinduksi aritmia ventrikel saat SEF. Dan jika hanya menganalisis pasien dengan presentasi klinis asimtomatik saja maka event free survival pada kelompok yang tidak terinduksi adalah $99.2 \%$ hingga $100 \%$ pada $1,5,10$ dan 15 tahun. Atas dasar itu disimpulkan bahwa SEF merupakan prediktor yang baik pada pasien dengan sindrom Brugada baik yang asimtomatik maupun dengan presentasi klinis sinkop.

Belhassen $\mathrm{dkk}^{10}$ menyebutkan bahwa studi di atas menjadi begitu penting dalam memutuskan kontroversi manfaat SEF pada pasien sindrom Brugada karena (1) studi di atas berasal dari laboratorium tempat sindrom Brugada pertama kali ditemukan, (2) studi itu merupakan studi senter tunggal dengan besar sampel yang terbanyak dan waktu pengamatan yang terlama (20 tahun), (3) hasil studi itu sejalan dan bahkan menguatkan studi serupa yang dilakukan oleh Brugada bersaudara 12 tahun yang silam, dan (4) artikel studi itu melakukan diskusi yang adil terhadap

\section{Spontaneous Type 1 ECG}

\section{Symptomatic}

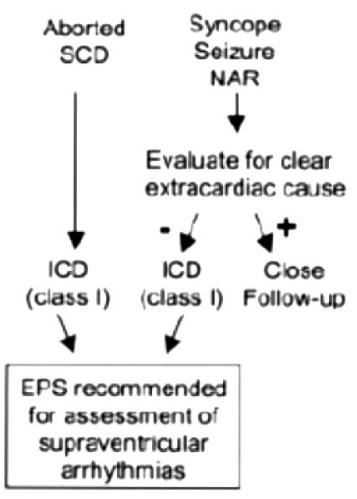

Asymptomatic

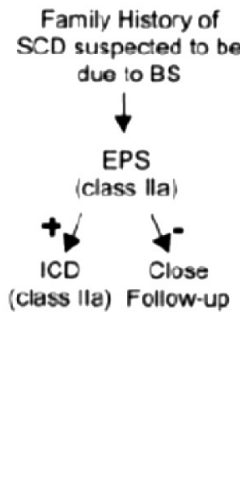

No Family History

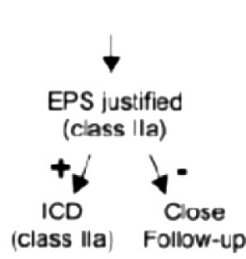

Sodium Channel Block-induced Type 1 ECG

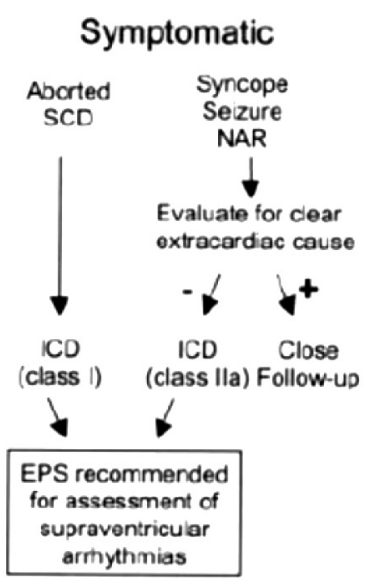

Asymptomatic

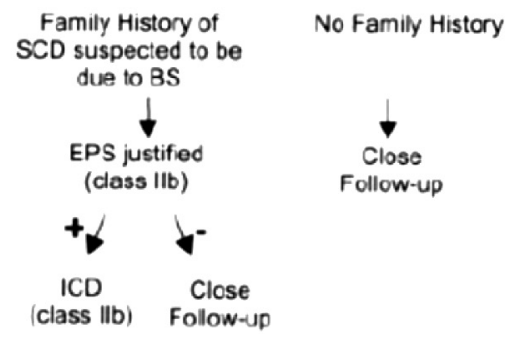

Gambar 1. Diagram indikasi studi elektrofisiologi pada sindrom Brugada berdasarkan panduan tahun 2013. 
hasil yang berbeda dari studi-studi sebelumnya. Diingatkan juga bahwa agar mendapat nilai prediksi yang setara dengan laporan Sieira dkk maka sangat penting untuk melakukan protokol SEF sesuai dengan protokol mereka.

Studi Sieira dkk beranjak dari keterbatasanketerbatasan yang ditemui pada studi-studi sebelumnya, dilakukan dengan metodologi yang baik. Hasil studi ini kemungkinan akan mengubah panduan praktik klinik dalam tatalaksana sindrom Brugada di masa yang akan datang.

\section{Daftar Pustaka}

1. Brugada J, Brugada R, Brugada P. Determinants of sudden cardiac death in individuals with the electrocardiographic pattern of Brugada syndrome and no previous cardiac arrest. Circulation 2003;108(25):3092-6.

2. Priori SG, Gasparini M, Napolitano C, Della Bella P, Ottonelli AG, Sassone B, et al. Risk stratification in Brugada syndrome: results of the PRELUDE (PRogrammed ELectrical stimUlation preDictive valuE) registry. J Am Coll Cardiol 2012;59(1):3745.

3. Probst V, Veltmann C, Eckardt L, Meregalli PG, Gaita F, Tan $\mathrm{HL}$, et al. Long-term prognosis of patients diagnosed with Brugada syndrome: Results from the FINGER Brugada Syndrome Registry. Circulation 2010;121(5):635-43.

4. Takagi M, Yokoyama Y, Aonuma K, Aihara N, Hiraoka M.
Clinical characteristics and risk stratification in symptomatic and asymptomatic patients with brugada syndrome: multicenter study in Japan. J Cardiovasc Electrophysiol 2007;18(12):124451.

5. Kamakura S, Ohe T, Nakazawa K, Aizawa Y, Shimizu A, Horie $\mathrm{M}$, et al. Long-term prognosis of probands with Brugada-pattern ST-elevation in leads V1-V3. Circ Arrhythm Electrophysiol 2009;2(5):495-503.

6. Gehi AK, Duong TD, Metz LD, Gomes JA, Mehta D. Risk stratification of individuals with the Brugada electrocardiogram: a meta-analysis. J Cardiovasc Electrophysiol 2006;17(6):57783.

7. Paul M, Gerss J, Schulze-Bahr E, Wichter T, Vahlhaus C, Wilde $\mathrm{AA}$, et al. Role of programmed ventricular stimulation in patients with Brugada syndrome: a meta-analysis of worldwide published data. Eur Heart J 2007;28(17):2126-33.

8. Fauchier L, Isorni MA, Clementy N, Pierre B, Simeon E, Babuty D. Prognostic value of programmed ventricular stimulation in Brugada syndrome according to clinical presentation: an updated meta-analysis of worldwide published data. Int J Cardiol 2013;168(3):3027-9.

9. Sieira J, Conte G, Ciconte G, de Asmundis C, Chierchia GB, Baltogiannis G, et al. Prognostic value of programmed electrical stimulation in Brugada syndrome: 20 years experience. Circ Arrhythm Electrophysiol 2015;8(4):777-84.

10. Belhassen B, Michowitz Y. Arrhythmic risk stratification by programmed ventricular stimulation in Brugada syndrome: the end of the debate? Circ Arrhythm Electrophysiol 2015;8(4):757-9. 